\title{
USO DO GEOPROCESSAMENTO PARA AVALIAÇÃO DA SUSCEPTIBILIDADE EROSIVA DA BACIA HIDROGRÁFICA DO CÓRREGO YPÊ - ILHA SOLTEIRA/SP
}

\author{
Adalto Moreira Braz ${ }^{1}$
}

Ketty Priscila Maiara Gadelha dos Santos ${ }^{2}$

\begin{abstract}
Vanessa Aparecida Julio ${ }^{3}$
\section{RESUMO}

O presente trabalho busca por meio do uso de técnicas de geoprocessamento integrar diferentes variáveis a fim de se obter um mapeamento de áreas susceptíveis à erosão na Bacia Hidrográfica do Córrego Ypê (ano de 2014), no município de llha Solteira, São Paulo. O mapeamento de susceptibilidade erosiva de uma bacia hidrográfica depende de uma séria de condicionantes. Neste trabalho foram usadas as condicionantes de pedologia, declividade, geomorfologia e classes de uso e ocupação da terra. A bacia está localizada em uma região com forte presença do cultivo da cana-deaçúcar, além de estar presente tanto na área rural, como na área urbana deste município. Estes aspectos evidenciam ainda mais a necessidade de análises ambientais seguidas de mapeamentos quantitativos e qualitativos com o objetivo de identificar possíveis impactos ambientais e as influências no entorno da bacia hidrográfica do córrego Ypê, a fim de identificar irregularidades e propor melhorias, além de orientações em decisões futuras. Através do mapeamento de susceptibilidade erosiva, espera-se obter resultados satisfatórios quanto a áreas mais sujeitas à degradação ambiental, a fim que se tenham áreas prioritárias para um futuro estudo de planejamento ambiental desta bacia hidrográfica.
\end{abstract}

PALAVRAS-CHAVE: Geoprocessamento. Susceptibilidade Erosiva. Bacia Hidrográfica.

\footnotetext{
${ }^{1}$ Graduando do $8^{\circ}$ semestre do curso de Geografia (Bacharelado) pela UFMS/CPTL adaltobraz.geografia@gmail.com

${ }^{2}$ Graduanda do $6^{\circ}$ semestre do curso de Geografia (Bacharelado) pela UFMS/CPTL kettypriscila@hotmail.com

${ }^{3}$ Graduanda em Geografia (Bacharelado) pela UFMS/CPTL - vane.julio@hotmail.com
} 


\title{
USO DEL GEOPROCESSAMIENTO PARA LA EVALUACIÓN DE SENSIBILIDAD EROSIVA DEL CUENCA DEL RÍO YPE - ILHA SOLTEIRA / SP
}

\begin{abstract}
RESUMEN
Este estudio tiene como objetivo a través de la utilización de técnicas de SIG para integrar las diferentes variables con el fin de obtener un mapeo erosionable en la Cuenca Arroyo Ypê (2014), en el municipio de Ilha Solteira, São Paulo. El mapeo de la susceptibilidad erosiva de una cuenca depende de una serie de limitaciones. En este trabajo se han utilizado las limitaciones de la edafología, la pendiente, geomorfología y las clases de uso y ocupación del suelo. La cuenca se encuentra en una región con una fuerte presencia del cultivo de la caña de azúcar, además de estar presente tanto en zonas rurales como en las zonas urbanas del municipio. Estas cuestiones ponen de relieve la necesidad de un mayor análisis ambiental siguió cualitativa y cuantitativa con el fin de identificar los posibles impactos ambientales y las influencias que rodean las cuencas Ypê corriente con el fin de identificar las deficiencias y proponer mejoras asignaciones, además de orientación sobre las decisiones futuro. Mediante la cartografía de la susceptibilidad de erosión, se espera obtener resultados satisfactorios a medida que más zonas sujetas a la degradación del medio ambiente, a la que tienen las áreas prioritarias para el futuro estudio de la planificación ambiental en esta cuenca.
\end{abstract}

PALABRAS-CLAVE: Geoprocessing Erosive Susceptibility. Basin.

\section{GEOPROCESSING USE FOR ASSESSING SUSCEPTIBILITY EROSIVE BASIN STREAM YPÉ - ILHA SOLTEIRA / SP}

\begin{abstract}
This study aims through the use of GIS techniques to integrate different variables in order to obtain a mapping erodible in Watershed Stream Ypê (2014), in the municipality of Ilha Solteira, São Paulo. The mapping of erosive susceptibility of a watershed depends on a series of constraints. In this work the constraints of pedology, slope, geomorphology and classes for use and occupation of land were used. The basin is located in a region with a strong presence of the cultivation of sugar cane, besides being present both in rural as in urban areas of the municipality. These issues highlight the need for further environmental analysis followed qualitative and quantitative in order to identify potential environmental impacts and influences surrounding watershed stream Ypê in order to identify deficiencies and propose improvements mappings, in addition to guidance on decisions future. By mapping the erosive susceptibility, is expected to obtain satisfactory results as more areas subject to environmental degradation, to which have priority areas for future study of environmental planning in this basin.
\end{abstract}

KEYWORDS: GIS. Erosive susceptibility. Basin.

\section{INTRODUÇÃO}

A inserção do homem-sociedade no espaço urbano demanda adequações espaciais para que sua estada possa ser a mais "agradável" possível, e para que isto ocorra são levados em consideração fatores físicos, os quais condicionam fatores socioeconômicos e vice-versa, como proximidade a fontes de abastecimento de água 
potável, áreas planas para ocupação residencial e industrial, áreas livres de riscos ambientais, como inundações, deslizamentos, etc (ARAÚJO JÚNIOR, 2013).

A importância de se abordar esta temática para estudos do uso e ocupação da terra em bacias hidrográficas em espaço urbano revela uma preocupação cada vez mais constante com a análise integrada do meio ambiente, ameaçado pela expansão urbana, poluição de cursos d'água em bacias hidrográficas e impactos gerados pelo homem. As bacias hidrográficas que fazem parte do meio urbano são ainda mais ameaçadas, com deposições constante de lixo, vulneráveis à canalização (principalmente pela expansão urbana), obras mal sucedidas para evitar enchentes etc. O caso da bacia hidrográfica do córrego Ypê, chama atenção por ser uma bacia que possui nascentes no meio urbano e também no meio rural. Além de possuir em sua maior extensão o cultivo intenso da cana-de-açúcar e uma nascente recémurbanizada com um novo loteamento na cidade.

Estes aspectos evidenciam ainda mais a necessidade de análises ambientais seguidas de mapeamentos quantitativos e qualitativos com o objetivo de identificar possíveis impactos ambientais e as influências no entorno da bacia hidrográfica do córrego Ypê, a fim de identificar irregularidades e propor melhorias, além de orientações em decisões futuras. Por fazer parte deste cenário, o córrego Ypê recebe influência direta da área urbana, têm uma perspectiva de expansão prevista no Plano Diretor Municipal como área de interesse estratégico para o município de Ilha Solteira.

\section{Localização da Área de Estudo}

A Bacia Hidrográfica do Córrego Ypê localiza-se entre as coordenadas $20^{\circ} 24^{\prime}$

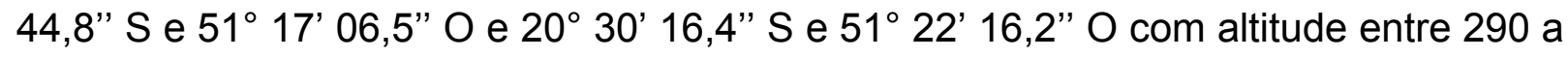
370m acima do nível do mar (SANTOS e HERNANDEZ, 2013). Localizada entre plantios de cana-de-açúcar e em algumas localidades adentrando o perímetro urbano de ilha solteira. A bacia possui uma área de 5714,65 ha ou $57,14 \mathrm{~km}^{2}$ (Figura 01). 
Figura 01 - Mapa de localização da Bacia Hidrográfica do Córrego

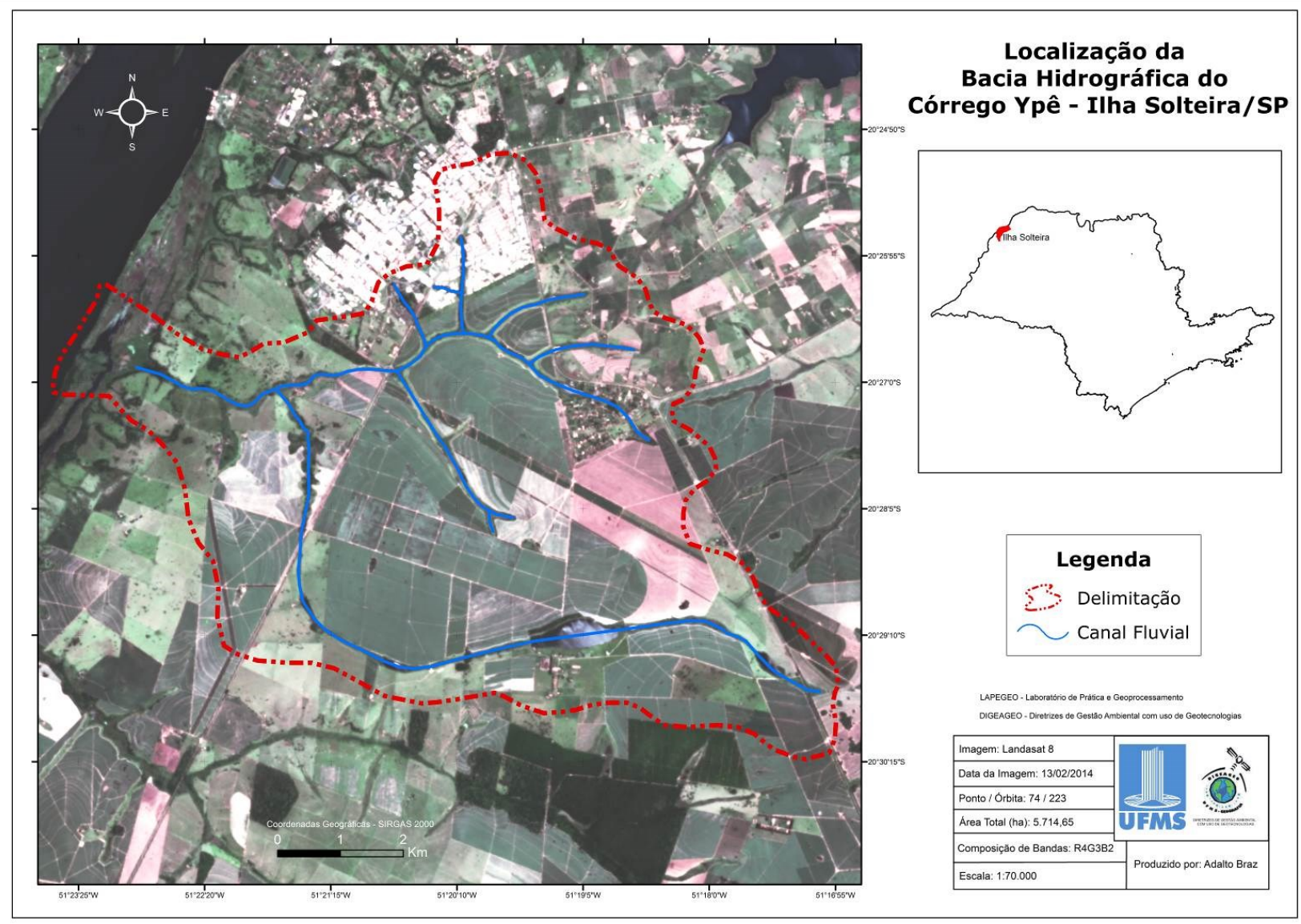

Fonte - BRAZ, A. M. (2014).

\section{METODOLOGIA E APLICAÇÃO}

Neste estudo foi feito inicialmente a escolha da área pesquisada, através de imagens de satélite (Landsat 8 e Google Earth). Para a análise e extração da delimitação da bacia hidrográfica, foi utilizado o SIG Global Mapper 11. Para isso foi usada imagem de radar da missão SRTM (SF-22-V-B), disponibilizadas pela Embrapa (Projeto Brasil em Relevo).

O próximo passo foi realizar o processamento digital da imagem da imagem do satélite Landsat 8 . Foi usada a composição RGB nas bandas 4,3 e 2 respectivamente. As bandas brutas do satélite possuem $30 \mathrm{~m}$ de resolução espacial, para uma análise mais apurada após a composição das bandas 432, incluiu-se uma nova banda na composição, a banda 8 (pancromática, com $15 \mathrm{~m}$ de resolução espacial), chegando à uma composição fusionada final com a composição R4G3B2 com resolução espacial 
de 15m. A imagem do satélite foi imageada na data 13/02/2014 e corresponde ao ponto 74 e órbita 223. As imagens foram obtidas no site Earth Explorer (NASA). Para a classificação digital da imagem foi usado o SIG ENVI EX 4.8, na qual foi responsável pela aplicação da classificação orientada a objeto, que resultou no mapeamento de uso e ocupação do solo da Bacia Hidrográfica do Rio Come Onça.

O procedimento de classificação orientada a objetos $(\mathrm{O})$ se dá com a indicação de segmentos para determinadas classes, sendo esses usados como amostras. No processo de classificação OO, o algoritmo classificador irá se basear nos conceitos de resolução espacial, resposta espectral e textura/tamanho dos objetos na qual se encontram dentro das amostras coletadas.

O mapeamento de declividade foi obtido com o auxílio do SIG ArcGIS. Foi utilizada também, imagem SRTM (90 metros) para este procedimento.

Os dados referentes à geomorfologia foram adquiridos da base de dados do IBGE-Geociências (Instituto Brasileiro de Geografia e Estatística), e os dados referentes à pedologia foram adquiridos do Mapa de Solos do Brasil - 2011, disponibilizado pela EMBRAPA.

O mapeamento de susceptibilidade erosiva de uma bacia hidrográfica depende de uma séria de condicionantes. Neste trabalho foram usadas as condicionantes de pedologia, declividade, geomorfologia e classes de uso e ocupação da terra. Todos estes fatores influenciam diretamente na maior ou menor susceptibilidade erosiva do ambiente em que atuam. Para a elaboração do mapa de susceptibilidade erosiva, foram elaborados diferentes valores referentes aos pesos em que cada classe irá exercer sobre o ambiente. Os pesos de cada classe foram estipulados em valores de 1 a 5, conforme ROSS (1994). Ross sistematizou uma hierarquia de fragilidade, representada por classes: muito fraca (1), fraca (2), média (3), forte (4) e muito forte (5) de acordo com seu grau de influência no ambiente. Assim, cada variável se diferencia em importância e relação com a susceptibilidade erosiva (Tabela 01). Para esta pesquisa, adaptou-se a quantidade dos pesos para que ficassem de acordo com a realidade da bacia analisada (Tabela 02 ). 
Tabela 01 - Análise dos pesos de susceptibilidade erosiva

\begin{tabular}{c|c}
\hline \multicolumn{2}{c}{$\begin{array}{c}\text { Determinação e Análise dos pesos } \\
\text { de Susceptibilidade Erosiva }\end{array}$} \\
\hline Pesos & Categoria \\
\hline 1 & Baixa \\
\hline 2 & Média \\
\hline 3 & Alta \\
\hline
\end{tabular}

Fonte: BRAZ (2014), adaptado de ROSS (1994)

Tabela 02 - Caracterização das variáveis e pesos de susceptibilidade erosiva.

Fonte: BRAZ (2014)

\begin{tabular}{|c|l|c|}
\hline Plano de Informação & \multicolumn{1}{|c|}{ Variável } & Pesos \\
\hline \multirow{4}{*}{$\begin{array}{c}\text { Uso e Ocupação da } \\
\text { Terra }\end{array}$} & Floresta & 1 \\
\cline { 2 - 3 } & Água & 1 \\
\cline { 2 - 3 } & Varjão & 2 \\
\cline { 2 - 3 } & Pastagem & 3 \\
\cline { 2 - 3 } & Cultura Permanente & 3 \\
\cline { 2 - 3 } & Solo Preparado & 5 \\
\cline { 2 - 3 } & Área Urbana & 5 \\
\cline { 2 - 3 } & Cana & 2 \\
\hline \multirow{4}{*}{ Declividade } & Plano 0 a 3\% & 5 \\
\cline { 2 - 3 } & $\begin{array}{l}\text { Suave Ondulado 3 a } \\
\text { 8\% }\end{array}$ & 3 \\
\cline { 2 - 3 } & Ondulado 8 a 20\% & 3 \\
\hline \multirow{2}{*}{ Pedologia } & Latossolo Vermelho \\
& Distrófico & 3 \\
\cline { 2 - 3 } & Massa d'água & \\
\hline \multirow{2}{*}{ Relevo } & $\begin{array}{l}\text { Planalto Central da } \\
\text { Bacia do Paraná }\end{array}$ & \\
\hline
\end{tabular}

Alguns valores sofreram alterações em relação à metodologia consultada, para que ficassem de acordo com a influência que exercem sobre a área de estudo. Os valores finais quanto à susceptibilidade do ambiente foram elaborados a partir do cruzamento destes parâmetros estabelecidos para cada variável, a fim de se chegar a três graus de susceptibilidade do ambiente: Baixa, Média e Alta.

Os procedimentos metodológicos seguidos até se obter o mapeamento final (divididos em 4 níveis + resultados) são exemplificados no fluxograma abaixo (Figura 02). Como já dito anteriormente os dados geomorfológicos e pedológicos foram adquiridos nas bases do IBGE e Emprapa. Os dados de declividade foram gerados a partir do SIG ArcGIS, com dados da missão SRTM (também disponibilizado pela EMBRAPA). Todo o tratamento dos dados, cruzamento dos planos de informações 
contendo as variáveis e elaboração dos mapas finais, foram realizados no SIG ArcGIS.

Figura 02 - Procedimentos metodológicos para a elaboração do mapa de susceptibilidade erosiva na Bacia Hidrográfica do Córrego Ypê.

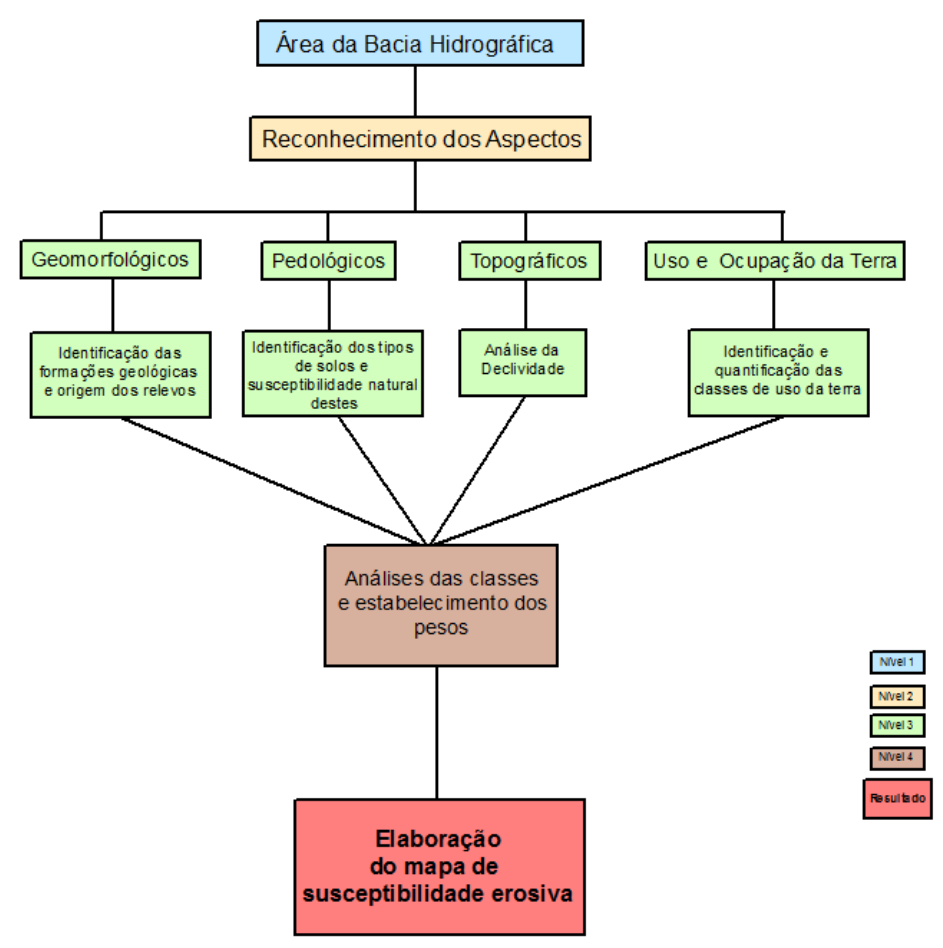

Fonte: Braz, A. M. (2014)

\section{RESULTADOS E DISCUSSÃO}

\section{CARACTERIZAÇÃO FISIOGRÁFICA}

A região de Ilha Solteira faz parte da Província Geomorfológica do Planalto Ocidental, conhecido como região das "zonas indivisas", com característica de relevo colinoso representado pelas rochas sedimentares do Grupo Bauru (LIMA et al., 2004). Quanto aos dados disponibilizados pelo IBGE, a bacia hidrográfica do córrego Ypê se encontra em uma área do Planalto Central da Bacia do Paraná, caracterizado por bacias e coberturas sedimentares.

Quanto à declividade da bacia, é em sua maior parte caracterizada pela classe Suave Ondulada (de 3 a $8 \%$ ), seguida da classe Plana (0 a 3\%). Isso acontece em 
função da localização muito próxima entre o encontro do Rio São José dos Dourados. As áreas de maior declividade (Suave Ondulada) e localizam-se no centro-norte da bacia, em sua maior parte próximas à área urbanizada.

Conforme estudos de SANTOS e HERNANDEZ (2013) única classe de solo encontrado na no entorno da bacia é a de Latossolo Vermelho (rico em sesquióxido). Os latossolos vermelhos apresentam cores vermelhas acentuadas, devido aos teores mais altos e à natureza dos óxidos de ferro presentes no material originário em ambientes bem drenados, e características de cor, textura e estrutura uniformes em profundidade.

\section{Uso e ocupação da terra}

Sua vegetação natural remanescente é composta na maior parte por mata úmida e floresta latifoliada semidecídua ou mata-seca (SANTOS e HERNANDEZ, 2013). Sendo a cana-de-açúcar fortemente cultivada no ao longo do município (Tabela 03).

A cultura se instalou na região de llha Solteira no ano de 2006, ocupando áreas com predomínio de áreas de pastagens. Lima et al. (2004) avaliaram em 43.228 ha de área de pastagem do município de llha Solteira, o que representa $66,79 \%$ da área total. Por meio da determinação do uso e da ocupação do solo na microbacia foi possível obter que a área apresentou mudança no uso do solo, apresentando $48,1 \%$ da área compreendida com a cultura da cana-de-açúcar, cultura esta inexistente na região, em anos anteriores (SANTOS e HERNANDEZ, 2013).

Próxima à área urbana e dentro da delimitação da bacia hidrográfico do córrego Ypê, mais recentemente foi introduzida em uma estreita faixa o cultivo de seringueiras. Em menor extensão, encontram-se ao sul da bacia e a oeste da bacia, algumas áreas de pastagem (Figura 03).

O uso e ocupação do solo, principalmente das áreas urbanas e das áreas de pastagens não conservadas influenciam a qualidade da água da microbacia do Córrego do Ipê, comprometendo a qualidade da água para fins de irrigação, especialmente no período chuvoso, aumentando a concentração de ferro total e sólidos suspensos em até $418 \%$ e 408,9\%, respectivamente, se comparada as condições normais. [...] A microbacia recebe influência de duas condições distintas, sendo parte de área urbana do município de Ilha Solteira e a maior parte de influencia rural onde se tem agricultura com predomínio de cultura de cana-de-açúcar e agropecuária. (SANTOS et al. 2011) 
Assim, o mapeamento de uso e ocupação da terra foi fundamento para entender a dinâmica e a espacialização dos elementos e diferentes ambientes que ocupam o entorno do canal, as nascentes e toda a área da bacia hidrográfica.

\section{Susceptibilidade Erosiva}

A categoria de susceptibilidade predominante na bacia é a de grau Médio, representando $56 \%$ da ocupação total da bacia (Tabela 04). É importante ressaltar que as variáveis de solo e geomorfologia, apresentam apenas uma classe ao longo da bacia hidrográfica do córrego Ypê, neutralizando em partes variações de susceptibilidade. Contrapondo a isso, as classes que maior influenciaram na análise foram as de uso e ocupação da terra e declividade. Ficando claro que as áreas com alto grau de susceptibilidade encontram-se nas áreas com maior declividade, e com maior peso de uso, como é o caso, por exemplo, nos entornos das APPs, que apresentam maior porcentagem de declividade e dão ocupação à cultura de cana-deaçúcar. Outro caso semelhante, ocorre nos espaços em que as classes representadas por área urbanizada e pastagem estão presentes. Já que na elaboração e interpolação dos dados, estas áreas (assim como a cultura de cana-deaçúcar) possuem pesos mais elevados. Entendidas como as duas classes que mais influenciam na susceptibilidade da bacia (Figura 04).

Tabela 04 - Valores obtidos na análise de Susceptibilidade Erosiva

\begin{tabular}{ll|c|c}
\hline \multicolumn{3}{c}{ Susceptibilidade Erosiva } \\
\hline $\begin{array}{c}\text { Grau de } \\
\text { Susceptibilidade }\end{array}$ & $\begin{array}{c}\text { Área } \\
\text { (ha) }\end{array}$ & $\begin{array}{c}\text { Área } \\
\text { (\%) }\end{array}$ \\
\hline Baixa & 224,66 & $4 \%$ \\
\hline Média & $3.216,54$ & $56 \%$ \\
\hline Alta & $2.273,96$ & $40 \%$ \\
\hline Total & $5.715,17$ & $100 \%$ \\
\hline
\end{tabular}

Fonte: BRAZ (2014) 
Figura 04 - Mapa de susceptibilidade erosiva da Bacia Hidrográfica do Córrego Ypê.

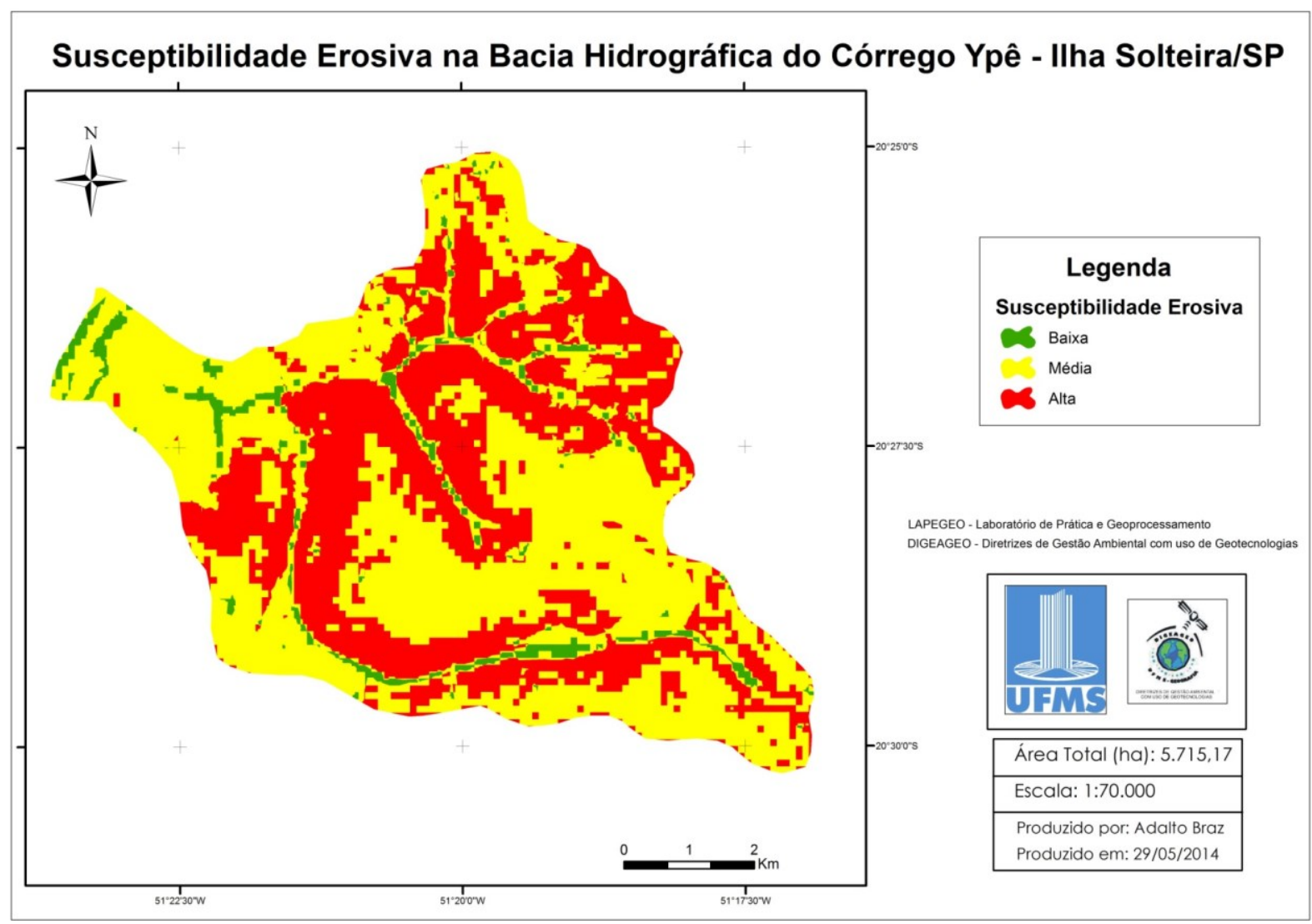

Fonte - BRAZ, A. M. (2014)

\section{CONSLUSÃO}

A Bacia Hidrográfica do Córrego Ypê, apresenta altos índices de susceptibilidade erosiva, visto que esta é uma bacia circundada por agricultura de cana-de-açúcar, além de fazer parte da área urbana do município de Ilha Solteira.

A expansão das áreas urbanas é preocupante visto que acarreta em inúmeros impactos ambientais. O município de llha Solteira aponta, em seu Plano Diretor, a área da microbacia como local estratégico para expansão da área urbana. Para Poleto (2003) a expansão das áreas urbanas próximo a corpos hídricos acarreta em uma das suas principais causas na degradação qualitativa e quantitativa (SANTOS e HERNANDEZ, 2013).

Dentre as medidas preventivas, inicialmente podemos destacar a preservação e conservação das APPs, além do reflorestamento destas áreas, visto que em sua maioria, estas áreas encontram-se apenas com vegetação rasteira. Além de ser 
possível de se pensar em medidas hidroagrícolas nesta bacia. Já que a agricultura de cana-de-açúcar pode gerar impactos de diversas naturezas sobre esta bacia, como por exemplo, através de queimadas, deposição de agrotóxicos próximos aos cursos d'água e ainda a agricultura mecanizada no entorno desta bacia.

Contudo, o mapeamento de susceptibilidade erosiva se mostrou uma ferramenta eficaz para a análise integrada dos fatores ambientais da bacia, tendo que, mapeamentos deste cunho podem servir como importantes dados/informações para se pensar no planejamento urbano e regional em bacias hidrográficas, já que o mesmo integra diferentes variáveis naturais e antrópicas. Além disso, o mapeamento de susceptibilidade pode servir como um norte para análises de ambientes com maior urgência para se lançar diretrizes para o planejamento ambiental.

\section{REFERÊNCIAS}

ARAÚJO JÚNIOR, A. C. R. GEOMORFOLOGIA URBANA E PLANEJAMENTO AMBIENTAL NA CIDADE DE BELÉM-PA. In: XIII Simpósio Nacional de Geografia Urbana, 2013, Rio de Janeiro. Anais do XIII Simpósio Nacional de Geografia Urbana. Rio de Janeiro: Editora da Universidade do Estado do Rio de Janeiro (EDUERJ), 2013.

HERNANDEZ, F. B. T.; SOUZA, S. A. V. de; ZOCOLER, J. L.; FRIZZONE, J. A. Simulação e efeito de veranicos em culturas desenvolvidas na região de Palmeira d'Oeste, estado de São Paulo. Engenharia Agrícola, v.23, p.21-30, 2003.

IBGE - Cidades (Ilha solteira, SP).

KLINTOWITZ, D. RELATÓRIO DE AVALIAÇÃO PLANOS DIRETORES DO MUNICÍPIO DE ILHA SOLTEIRA. Rede Nacional de Avaliação e Capacitação para Implementação dos Planos Diretores Participativos. Estado de São Paulo, 2009.

LIMA, E. A. C. F.; SILVA, H. R.; ALTIMARE, A. L. Uso atual da terra no município de llha Solteira, SP, Brasil: riscos ambientais associados. Holos Environment, v.4, p.81-96, 2004.

MIRANDA, E. E. de; (Coord.). Brasil em Relevo. Campinas: Embrapa Monitoramento por Satélite, 2005. Disponível em: <http://www.relevobr.cnpm.embrapa.br>. Acesso em: 15/04/2014.

ROSS, J. L. S. Análise Empírica da Fragilidade dos Ambientes Naturais e Antropizados. Revista do Departamento de Geografia. São Paulo: FFLCH-USP, nº, 1994.

SANTOS, G. O.; HERNANDEZ, F. B. T.; ROSSETTI, J. C. Balanço hídrico como ferramenta ao planejamento agropecuário para a região de Marinópolis, noroeste do estado de São Paulo. Revista Brasileira de Agricultura Irrigada, v.4, p.142-149, 2010.

SANTOS, G. O. ; HERNANDEZ, F. B. T. ; FRANCO, R. A. M. . Influência da Precipitação na Qualidade da Água para fins de Irrigação na Microbacia do Córrego do Ipê, Ilha Solteira - SP. In: XXI Congresso Nacional de Irrigação e Drenagem, 2011, Petrolina. XXI Congresso Nacional de Irrigação e Drenagem, 2011. 
SANTOS, G. O. ; HERNANDEZ, F. B. T. Uso do solo e monitoramento dos recursos hídricos no córrego do Ipê, Ilha Solteira, SP. Revista Brasileira de Engenharia Agrícola e Ambiental (Online), v. 17 , p. $60-68,2013$

SANTOS, H. G. dos. et al. O novo mapa de solos do Brasil: legenda atualizada. — Dados eletrônicos. - Rio de Janeiro : Embrapa Solos, 2011. 67 p. - (Documentos / Embrapa Solos, ISSN $1517-2627 ; 130)$

USGS-Nasa. Landsat 8. Disponível em: <http://earthexplorer.usgs.gov/>. Acesso em: 13/03/2014. 